Orbis Tertius, vol. XXIV, nº 29, e106, mayo-octubre 2019. ISSN 1851-7811

Universidad Nacional de La Plata

Facultad de Humanidades y Ciencias de la Educación

Centro de Estudios de Teoría y Crítica Literaria

\title{
La revista Sherlock Holmes y la configuración del lector de policial
}

\section{Sherlock Holmes magazine and the setup of police story readership}

\section{Andrea Vilariño}

Universidad de Buenos Aires, Argentina

vilarinoandrea@yahoo.com.ar

\section{Resumen:}

La revista Sherlock Holmes, semanario que se editó entre 1911 y 1913, fue la primera publicación, editada en Buenos Aires, dedicada exclusivamente a la crónica y el relato policial. Este rasgo la convierte en un material privilegiado para estudiar cómo se conforma el campo del género a comienzos del siglo XX. En este artículo, nos proponemos analizar de qué manera la revista contribuyó al proceso de conformación de un público lector aficionado a las ficciones criminales. En este sentido, consideramos que Sherlock Holmes construyó, a partir del despliegue de una serie de estrategias, un lector modelo que, basado en la matriz perceptiva del policial clásico, promovió sus modos de leer.

Palabras clave: Revista Sherlock Holmes, Género policial, Crónica, Lectores, Literatura y periodismo.

\section{Abstract:}

Sherlock Holmes, a weekly magazine which was published between 1911 and 1913, was the first publication edited in Buenos Aires that was devoted exclusively to chronicles and police stories. Lis feature makes it prime material to study how the field of gender is shaped at the beginning of the 20th century. In this article, we intend to analyze how the journal contributed to the process of formation of a readership fond of crime fiction. In this sense, we consider that, through different strategies, Sherlock Holmes built a model reader who promoted such readings upon the perceptual matrix of classic crime fiction.

Keywords: Sherlock Holmes Magazine, Police gender, Chronicle, Readers, Literature and journalism.

A mediados del año 1911, cuando comienza a publicarse la revista Sherlock Holmes, ${ }^{1}$ el campo periodístico argentino se halla prácticamente consolidado. ${ }^{2}$ En Buenos Aires circulan aproximadamente más de trescientas publicaciones periódicas entre diarios y revistas; en la mayoría de ellas, de alguna u otra forma, está presente la crónica policial y, en ocasiones, también el relato de crímenes. Desde fines del siglo XIX, el interés por las noticias e historias sobre asesinatos y otros delitos formaba parte del imaginario urbano y, la prensa, en general, daba cuenta de ello. En 1879, La Patria Argentina había inaugurado su sección "Variedades policiales" escrita por Eduardo Gutiérrez y, hacia 1904, el diario La Prensa incorporaba la suya, denominada "Noticias de policía". Los editores de Caras y Caretas percibían este interés claramente y escribieron, a propósito de la publicación, en 1899, de la crónica "Fusilamiento del parricida Chánez", lo siguiente:

Pero sea que semejante anhelo [...] tenga su origen en una degeneración o desequilibrio psicológico, manifestado por la necesidad de emociones fuertes; sea que esa ansiedad con que el lector de historias sangrientas espera que el criminal sea castigado, obedezca a un obscuro y no claramente definido instinto de justicia, el hecho es que todas las noticias referentes a los últimos momentos de Antonio Chánez, han sido devoradas con el mismo interés por los lectores de todas clases... (“Actualidad uruguaya. Fusilamiento del parricida Chánez", en Caras y Caretas, 30 de diciembre de 1899. Citado en Rogers, 2008, p. 179).

Para Caras y Caretas, "[e]ra la malsana curiosidad del público la que obligaba al periodista a internarse en los pormenores de un crimen para escribir la crónica. Cabía preguntarse entonces -decía- si el periodismo sólo respondía a lo que los lectores deseaban o si eran éstos los conducidos a leer lo que aquel ofrecía" (Rogers, 2008, p. 178). No obstante, ya sea por uno u otro motivo, es evidente que el periodismo de principios de siglo $\mathrm{XX}$ ya había incorporado todo aquello relacionado con el mundo del crimen. 
En este contexto hace su aparición, el 4 de julio de 1911, el primer número de la revista Sherlock Holmes que, consciente de las posibilidades que otorga un mercado editorial ávido de este tipo de publicaciones, formula una propuesta original orientada casi exclusivamente a "lo policial": ${ }^{3}$

[Sherlock Holmes] No viene á crear una necesidad, sino que surge, como consecuencia de una necesidad que existe; como consecuencia de esa misma necesidad que en todas partes del mundo ha actualizado en esta forma la crónica, y ha dado vida á las mil revistas de su índole, que particularmente en Inglaterra y Norte América, se han hecho de lectura indispensable para todas las clases sociales (Sherlock Holmes, "Sus propósitos", año I, nº 1, 4 de julio de 1911, p. 1).

El primer gesto que corrobora este propósito se plasma en la elección del nombre: Sherlock Holmes. Dicha elección responde al reconocimiento de la emergencia de un campo de lectura fértil en nuestro país, el del género policial, que encontraba en el personaje de Conan Doyle una figura emblemática. ${ }^{4}$ La revista se apartaba, de esta forma, de una denominación que evocara al sensacionalismo - predominante en la época en este tipo de publicaciones $-{ }^{5}$ para convocar al lector a un nuevo pacto de lectura. Como señala en su editorial: "Basta el nombre para definir la índole de esta publicación" (Sherlock Holmes, "Sus propósitos", año I, No 1, 4 de julio de 1911, p.1). En este nuevo pacto de lectura, la revista apela a un lector conocedor del género al que convoca a participar de una compleja red de relaciones intertextuales que remiten al policial.

Asimismo, al apelar a un lector conocedor del género, se recupera un modo de leer particular que se inicia, según Borges, en el origen de la ficción policial. En "El cuento policial", el escritor argentino afirma que con los primeros relatos detectivescos de Poe surge un tipo de lector nuevo: el lector de ficciones policiales. Un lector que lee "con incredulidad, con suspicacias, una suspicacia especial". Un lector, sostiene Borges, que si lee "En un lugar de la Mancha..., desde luego supone que aquello no sucedió en La Mancha", que si luego agrega más adelante- lee “...de cuyo nombre no quiero acordarme..." interpreta "¿por qué no quiso acordarse Cervantes? Porque sin duda Cervantes era el asesino, el culpable” (Borges, 1978, s/n). Ese lector, que emerge con el advenimiento de la literatura policial en el siglo XIX, surge, como ya se señaló, con los textos de Poe. En este sentido, los lectores de ficciones policiales, plantea Borges, "somos una invención de Edgar Allan Poe" (1978).

En nuestro país, ese lector de policial comienza a configurarse, si seguimos a Borges, en las últimas décadas del siglo XIX con la publicación de las primeras traducciones de Poe a cargo de Carlos Olivera a las que siguieron las de otros autores del género ${ }^{6}$ y, especialmente, con la edición en folletín de la primera novela policial, La huella del crimen de Luis Varela, bajo el seudónimo de Raúl Waleis. Además de Waleis/Varela, una importante cantidad de autores comienza a escribir relatos policiales: Holmberg, Groussac, Monsalve y el mismo Olivera, entre otros. Estas incursiones tempranas del género, sumadas a la difusión de la crónica y otros géneros cercanos al policial, fueron estructurando un público con determinadas exigencias, con algunas ideas muy precisas sobre las leyes y los requisitos del género (Lafforgue y Rivera, 1996, p. 13), y posibilitaron la emergencia de un modo de leer novedoso. Consideramos que la revista Sherlock Holmes, surgida en un momento clave del desarrollo del policial argentino, contribuyó, desde su propuesta editorial, a la construcción de ese modo de leer y, por ende, a la consolidación de una zona de ese campo literario en formación.

En Lector in Fabula, Umberto Eco propone la noción de lector modelo para dar cuenta de las operaciones que se realizan en un texto para prever un lector "capaz de cooperar en la actualización textual de la manera prevista por él y de moverse interpretativamente de la misma manera en la que él se ha movido generativamente" (Eco, 2013, p. 74). Para esto, se recurre a diferentes medios: la elección de una lengua, de un tipo de enciclopedia (conjunto de conocimientos compartidos), de determinado patrimonio léxico y estilístico y, también, a partir de proporcionar ciertas marcas distintivas de género que seleccionan a la audiencia. En este sentido, señala Eco, por un lado, el autor presupone la competencia de su lector modelo, pero, por el otro, también lo instituye (Eco, 2013). Incorporando un lenguaje coloquial -que apela a un lector 
popular- pero también, dando cuenta de una serie de decisiones particulares en cuanto al tratamiento de lo policial, Sherlock Holmes delimita claramente a su lector modelo desde su editorial inaugural:

\begin{abstract}
El mundo corre tras de estos incidentes de la vida, arrastrado por la curiosidad; y allí donde hay un hecho policial cualquiera hay mil espectadores que siguen, escalonando la intensidad de sus nervios, las peripecias cómicas, dramáticas, trágicas de la investigación; convertido cada uno en pesquisante que hace mentalmente el proceso del hecho, establece con sus conjeturas, las causas; crea, á su idea, la escena; señala con su lógica, el autor; define, con su pensamiento, los cómplices, y en una palabra, se substrae ante la consideración del suceso, á su misma existencia, para insumirla en la de los actores de la escena que las batallas de la vida dibujan á diario en la superficie de su mismo mundo (Sherlock Holmes, "Sus propósitos", año I, nº 1, I, 4 de julio de 1911, p. 1).
\end{abstract}

Ese espectador, que no es simplemente un participante pasivo de los acontecimientos que se desarrollan a su alrededor, sino que conjetura, que sospecha, que, en términos de Borges, se maneja con suspicacia, será el lector modelo perfilado por la revista. Asimismo, en esta representación que Sherlock Holmes propicia, no sólo se configura un público lector, sino que también se instaura un modo de leer que constriñe a sus receptores a una lectura anclada en la matriz perceptiva ${ }^{7}$ del policial clásico. Cada lector se convertirá, así, en un pesquisante y replicará el lugar en el que se instala el cronista en particular y la revista en general. Sherlock Holmes reúne de esta manera las vertientes genéricas más importantes de, en términos de Daniel Link, el campo de lo policial en el período. Link sostiene que "lo policial" constituye una categoría más amplia que la relacionada con la literatura, ya que atraviesa diversas matrices genéricas como la crónica, las películas, las series de televisión, las historietas, etc. (2003, p. 11). A comienzos del siglo XX, las dos formas discursivas predominantes que vehiculizan el género son la crónica periodística y el cuento policial. Precisamente, estas son las formas sobre las que se articula la revista. Su nombre convoca, por un lado, al personaje de Conan Doyle, mientras que, por el otro, se convierte en el referente de la labor periodística que emprende. En ese sentido, en la figura del pesquisante se conjugan el periodista y el detective:

SHERLOCK HOLMES, hará su pesquisa propia; intervendrá en todas las incidencias de la vida policial metropolitana, para reconstruir con sus datos, la escena en sus más mínimos detalles; para presentarla con todos sus matices de novela; con toda su intensidad de delito; y no será motivo de transgresión á su propósito, ninguna de las causas que producen el silencio alrededor de ciertos hechos que conmueven una población (Sherlock Holmes, "Sus propósitos", año I, no 1, I, 4 de julio de 1911, p. 1).

En consonancia con esta premisa, el periodista será aquél capaz de intervenir "en la vida policial metropolitana" para reconstruir cada escena derivada de la violencia urbana y hacerla inteligible al lector, y puede realizar esto porque, en tanto detective, es capaz de leer los signos que posibilitan revelar "la verdad" del crimen en una ciudad que se percibe cada vez más amenazante. ${ }^{8}$ Dicha percepción se funda en la sensación de caos que deriva de vivir en una metrópoli que ha estado creciendo exponencialmente desde fines del siglo XIX, producto de las políticas de inmigración llevadas a cabo durante el período. ${ }^{9}$ El crecimiento demográfico ha funcionado como elemento disparador para la construcción de un imaginario social que vincula en forma directa el desarrollo de la ciudad y el crecimiento del delito. ${ }^{10}$ Desde los inicios del siglo XX, este tópico ha estado presente en la prensa de circulación masiva, especialmente en las secciones vinculadas a la crónica del delito. ${ }^{11}$ En esta representación de la metrópoli en la prensa, se torna imprescindible contar con la presencia de aquel capaz de descifrar la ciudad, capaz de leer en ella las huellas del crimen y, así, desarticular la amenaza. El arte de leer las huellas es, precisamente, el método principal con el que opera el investigador del policial clásico. A través de él, interpreta aquellos signos que resultan insignificantes y pasan desapercibidos para el hombre corriente (Alwin, 1982). En esta primera etapa del género, lectura se homologa a desciframiento. El detective descifra el código de una escritura secreta que devela el misterio y, en esta operación, se transforma en un lector privilegiado de las huellas del crimen en la ciudad. La revista se inscribe en esta tradición del policial, pero transforma al detective clásico en periodista: 


\begin{abstract}
Sherlock Holmes no ha muerto. Investiga siempre. Pero ahora no es propiamente detective. Es periodista. Claro que Sherlock Holmes no es sajón, sino latino. Y no lo decimos arbitrariamente, muchas cualidades de su temperamento, son de países del sol. Ya conocen al héroe nuestros lectores. El hacerle inglés, con su pipa y su cara afeitada, y sus verdes ojos escrutadores, y su gesto hermético de hombre inductivo, el darle esa apariencia de glentleman británico, con su gardenia y su "monocle" fué cosa de Conan Doyle. Tampoco reside en Londres, nuestro admirable ex detective. Ahora vive en Buenos Aires y hace periodismo vibrante, ágil, informativo, nuevo... (Sherlock Holmes, "Un reporter ex detective. Las adivinas en Buenos Aires", año III, nº 93, 8 de abril de 1913).
\end{abstract}

Sherlock Holmes "no ha muerto", se ha reconfigurado y en esta reconfiguración se vuelve periodista. Este desplazamiento de detective a reporter, por un lado, convierte al periodista en el héroe de la verdad enunciada en la crónica, pero, por el otro, instaura un pacto de lectura en relación con los regímenes de verdad de dicho relato. En términos de Link, el policial clásico es, en primera instancia, "un relato sobre el Crimen y la Verdad" y el detective, en este caso el periodista, es su garante (2003, p. 13). Por su parte, el juego propuesto instala a la crónica en una zona cercana a la ficción. De ahí que las crónicas publicadas por la revista apelen a la ficcionalización como procedimiento narrativo. Esta utilización de procedimientos ficcionales para la construcción de la crónica policial forma parte de la tradición periodística, tanto europea como americana, de comienzos de siglo XX e inicios del XX. ${ }^{12}$ Como señala Sylvia Saítta, la prensa de comienzos de siglo ensaya la narración de sucesos delictivos recurriendo a diversos géneros literarios. En este sentido, afirma lo siguiente: "La construcción de un referente junto con la necesidad de relatar hechos realmente sucedidos, convierten a la crónica policial en un género que apela a procedimientos ficcionales, típicos de la prosa literaria o los versos costumbristas, para hacer verosímil su narración” (Saítta, 2013, p. 196). José Antonio Saldías, colaborador de la revista en su doble función de escritor de ficciones y cronista, grafica muy bien estas estrategias narrativas en La inolvidable bohemia porteña cuando recuerda los consejos del periodista Ángel Méndez sobre la escritura periodística: «Sí, pero escúchame bien, el periodista escribe para el interés del público. Has leído diarios y novelas [...] Bueno. Ahí está la cosa, si de policía: Sherlock Holmes; si de Casa de Gobierno, recordá el cliché de esa información» (Saldías, 1968, p. 33). Cabe recordar que, como ha indicado Jorge Rivera (1986), dichos cruces deben leerse en el marco de la profesionalización del escritor que posibilitó la figura doble del escritorperiodista, que atraviesa a toda la prensa del período.

No obstante, el aspecto novedoso que plantea Sherlock Holmes, en relación con otras propuestas editoriales, es que dichos procedimientos se develan al lector, y, en ese gesto, se establece un juego con él, un juego que lo obliga a participar de las reglas del género; un juego especular en el que ambos, periodista y lector, cumplen el rol de detectives. El periodista, que es capaz de leer las huellas, los indicios, que conducen a la resolución del crimen, proporciona al lector los datos necesarios para hacerlo partícipe de la resolución del caso. De esta manera, desde la revista, la figura del detective, desdoblada en periodista/lector, se abre en dos dimensiones: por un lado, como el detective que lee los vínculos entre la ciudad y el crimen (el cronista de policial), y, por el otro, como el detective que, como lector "empírico", descifra el enigma a partir de los elementos que le proporciona dicho cronista.

Ricardo Piglia ha analizado la figura del detective como lector empírico a través del personaje de Dupin. Para el escritor, el detective de Poe es un lector que se encuentra en tensión con el escenario de la ciudad, entendida como el espacio de la sociedad de masas. No obstante, es en ese espacio de la masa y de la multitud anónima donde surge su figura como la de un sujeto único: "el individuo excepcional, el que sabe ver (lo que nadie ve). $\mathrm{O}$, mejor, el que sabe leer lo que es necesario interpretar, el gran lector que descifra lo que no se puede controlar" (2005, p. 82). Debido a que es el primer detective literario, Dupin se establece como modelo de los que vendrán, es decir, prefigura a los detectives posteriores, especialmente a Sherlock Holmes. La revista recupera este modelo y lo hace intervenir en el juego de lectura que propone a su público lector.

En una metrópoli moderna como Buenos Aires, el semanario propicia no sólo un periodista que se ha transforma en detective, sino también un lector al que se le pide que lea como un detective. Piglia señala que los periódicos son el escenario cotidiano del crimen y sólo un refinado lector como Dupin podrá leerlos "como nadie los ha leído antes" (2005, p. 84). En esta línea, el periodista/detective de Sherlock Holmes leerá, también como lector experto, las huellas del crimen en la gran ciudad y las plasmará en la revista para que 
sean leídas de esa forma por los lectores. De esta manera, se establece un pacto de lectura que avala la verdad enunciada por la crónica y que se basa en un modo de leer que tanto periodista como lector comparten. Esto se percibe, especialmente, en aquellas crónicas en las que la revista asume la investigación del caso. En "La primera captura de Sherlock Holmes en Buenos Aires”, el cronista realiza una investigación sobre la fuga de la Penitenciaría Nacional de Planas y Virella, el anarquista que había sido detenido en 1907 por el atentado a Manuel Quintana:

SHERLOCK HOLMES ha hecho, pues, su más inteligente pesquisa. Él es detective, por sport. Ya lo hemos dicho. Ayudar á la policía sería desfigurar su misión, dándole á ésta un carácter utilitario. Por eso Planas Virella, el anarquista que atentó contra la vida de un Presidente de la Nación; el director de la evasión de la Penitenciaría; el más peligroso de los fugados estuvo en nuestro poder y ahora anda en libertad (Sherlock Holmes, año I, nº 6, 8 de agosto de 1911, pp. 63-64).

En este tipo de crónicas, no sólo se le posibilita al lector ser testigo de la investigación "en el mismo momento y bajo las diversas circunstancias en las que se lleva a cabo", sino, como ya mencionamos, se apela también a su participación para dilucidar los interrogantes del caso:

Dejamos al chauffeur y esta vez surgieron á nuestra imaginación estas dos preguntas: ¿Se habrían equivocado al dar la filiación el Gerente de la casa de préstamos y la hija del carbonero? ¿O los operadores habían encargado á dos cómplices la conversión de las alhajas y se habían puesto en salvo en una ciudad del interior donde estos últimos iban á buscarles? (Sherlock Holmes, "Los robos de alhajas se convierten en epidemia", año I, nº 1, 4 de julio de 1911, pp. 64-66).

Sin duda, esta interpelación forma parte de una estrategia editorial para posicionarse en el campo periodístico contemporáneo. Al ser una revista de circulación semanal, Sherlock Holmes se distancia de la pretensión de publicar "la primicia". Los casos que allí se presentan, en su mayoría, ya han circulado como crónica o noticia en los diarios citadinos. Por lo tanto, dicha interpelación se vuelve un recurso insoslayable para el funcionamiento exitoso de la revista que, consciente de su eficacia, perfila un lector modelo particular que, en ocasiones, es directamente explicitado en notas como la siguiente:

Desde que apareció el primer número de SHERLOCK HOLMES se ha desarrollado de un modo atroz la afición á ser detective. Ya había muchos ciudadanos pacíficos que se consideraban dotados del olfato de un lebrel y exclamaban, cuando tardaba la Policía en dar con un delincuente: "A ese lo hubiera prendido yo si me hubiesen confiado la pesquisa".

Pero desde que nuestras páginas han recreado á cientos de miles de lectores con sus narraciones sobre hazañas policiales, la cosa ha subido de punto y hoy día, de cada tres habitantes de Buenos Aires, hay por lo menos uno que considera lo más fácil encontrar al autor de cualquier crimen, aún cuando la Policía oficial haya fracasado (Sherlock Holmes, "Parte Preventivo", año $I, n^{\circ} 5,1$ de agosto de 1911, pp. 3-5).

Debido a ese pacto de lectura que se propone, cronista y lector comparten un modo de leer la "realidad" que está atravesado por la lógica del policial clásico:

\footnotetext{
Vamos a ver, lector: si tú -lo que pasa a cada rato- te encontraras de manos a boca con un espectáculo callejero como el que reproduce del natural nuestra fotografía, ¿qué pensarías? ¿Qué juicio te harás de ese compacto pelotón de gente que, estirando los cuellos, moviéndose nerviosamente, dando saltitos para ver mejor, se se (sic) estruja y aprieta en torno a la "causa desconocida" de casi todos los tumultos callejeros?

Lo menos que pensarías, lector bueno, sería en la realidad de un accidente. Tu imaginación, a poco que la hurgaras, te haría ver mentalmente algún cuerpo magullando y maltrecho, alguna triste víctima de los peligros del tránsito, algún herido en riña, algún desventurado fulminado por un cable. ¿Verdad? Pues bueno, tu desencanto al enterarte de la verdad será idéntico al que nosotros hemos sufrido. El mismo que sufrirás ahora, cuando te diga que toda esa multitud curiosa y ajustada no responde sino a este hecho espantable:

¡Un neumático que ha hecho explosión!

Quédete, ${ }^{13}$ lector, como a nosotros, el consuelo de tripas de hacer un poco de filosofía, recurriendo, como supremo argumento, al socorrido encogimiento de hombros del clásico "iqué me importa!"

Y hasta otra, lector bueno. (Sherlock Holmes, "Un casi enigma”, año III, no 84, 6 de febrero de 1913).
}

Por su parte, como ya señalamos, si bien la crónica policial y otros géneros afines que abordan el mundo de la violencia urbana ocupan un lugar preponderante en la revista, ésta se complementa con otras secciones 
de interés general como la de Teatro y Turf. Dichas secciones también se escriben desde una perspectiva inscripta en el modo de leer del lector de policial. Es decir, sus crónicas se plantean en términos de pesquisas. Por ejemplo, en la sección dedicada a "las cosas del turf" se señala: "Mucho campo tiene, en esa escena, la habilidad policial de SHERLOCK HOLMES"; y en lo que se refiere al teatro afirma: "Sherlock Holmes levantará también discretamente el cortinado de los camarines, y su acerada vista rebuscará las intimidades del teatro" (Sherlock Holmes, "Páginas complementarias", Año I, Nro. 1, 4 de julio de 1911, p. 2). En este sentido, el periodista nunca abandona su lugar de detective/pesquisante:

\begin{abstract}
Asesorado por viejos conocedores del oficio, nuestro hábil pesquisante se deslizará silenciosamente por entre los studs, parlamentará con los cuidadores, sondeará el pensamiento de los jockeys, para sorprender las infinitas cábulas y combinaciones que deciden en la pista los sorprendentes descalabros de la cátedra (Sherlock Holmes, "Páginas complementarias", año I, $n^{\circ} 1,4$ de julio de 1911, p. 2).
\end{abstract}

Asimismo, a las diversas estrategias ya mencionadas para interpelar a su lector modelo, se suma la de proponer su participación, a la manera de colaborador, en las investigaciones encaradas por la revista. En esta línea, se puede leer lo siguiente: "Para estas investigaciones Sherlock Holmes dispone de un nutrido séquito de auxiliares, y no será difícil que el mismo público sea el principal interesado en colaborar y contribuir en sus pesquisas" (Sherlock Holmes, "Páginas complementarias", año I, no 1, 4 de julio de 1911, p. 2). Algo similar ocurre en relación con las crónicas teatrales: "Pesquisante por hábito y por sport, nada escapará á su vista, y guiado por su discreción y su cultura, vivirá la comedia humana en amigable consorcio con sus actores, poniendo sus sutilezas al servicio de la verdad" (Sherlock Holmes, "Páginas complementarias", año I, no 1, 4 de julio de 1911, p. 2).

Por último, el mundo del policial al que remite la revista no se reduce al de la crónica nacional o extranjera, sino que incluye ficciones del género originales y traducciones de los principales autores extranjeros como Conan Doyle, Maurice Leblanc, Arthur Reeve, A. Freeman, entre otros. ${ }^{14}$ Cabe señalar, por su parte, que los cruces que se realizan en la revista entre crónica y relato son tan frecuentes que, en ocasiones, solamente los modos de diagramación permiten dilucidar si se trata de un género u otro. Ciertas crónicas son presentadas como relatos y, viceversa, muchos relatos se constituyen como crónicas. Consideramos que este cruce no sólo hace explícito los préstamos que se producen entre uno y otro género, sino que también organiza ciertos protocolos de lectura que establecen los parámetros desde los cuales leerlos. Como señala Chartier (1994), no existen textos fuera de los objetos escritos que lo dan de leer: "Los lectores sólo los encuentran inscritos en un objeto cuyos dispositivos y organización guían y constriñen la operación de producción del sentido" (1994, p. 20). La disposición de las páginas en la revista, las modalidades de relación entre el texto y su paratexto (títulos, pero también ilustraciones, fotografías, epígrafes, cuadros, etc.) remiten siempre al mundo literario del policial (ejemplo emblemático de esto lo constituye el logo de la revista que lleva la figura del detective de Conan Doyle). En este sentido, la construcción de sentido que realiza el lector se encuentra atravesada por estos dispositivos escriturarios que orientan su lectura hacia el modo de leer propio del género. Desde esta perspectiva, la inclusión de ilustraciones y fotografías es central para la organización de estos dispositivos. Desde fines del siglo XIX, las fotografías y las ilustraciones fueron incorporadas a la prensa masiva y ocuparon un rol privilegiado en aquellas publicaciones relacionadas con el delito. ${ }^{15}$ Sherlock Holmes continúa esta tradición e incorpora las ilustraciones tanto para la representación del caso policial abordado como para acompañar -a la manera de las revistas ilustradas europeas y americanas- los relatos que se incorporan a la revista.

Surgida en un momento de ascenso de la cultura de masas en nuestro país, la revista Sherlock Holmes se propuso intervenir en ella con una propuesta editorial novedosa que le permitió posicionarse en el mercado a través de un perfil diferente al de las publicaciones existentes. Al hacerlo, perfiló un lector modelo a través del cual propició un modo de leer vinculado al género policial. Con este propósito, ensayó una serie de estrategias tendientes a configurar un lector cada vez más consciente de los procedimientos y leyes del género. 
No obstante, aún está pendiente el estudio y la sistematización de los relatos que allí se publicaron durante sus dos años de existencia. Creemos que su estudio exhaustivo permitirá valorar los aportes de la revista a la conformación de un público lector de policial y contribuirá al conocimiento de esta etapa temprana del género en Argentina.

\section{REFERENCIAS}

Alwin, R. (1982). Problemas y figuras. Buenos Aires, Argentina: Editorial Alfa.

Benjamin, W. (2012) [1938]. El París del Segundo Imperio en Baudelaire. En El París de Baudelaire. Buenos Aires, Argentina: Eterna Cadencia Editora.

Borges , J. L. (1978) El cuento policial. Recuperado de http://borgestodoelanio.blogspot.com.ar/2015/05/jorge-luisborges-el-cuento-policial.html.

Brunetti , P. (2006). Relatos de prensa. La crónica policial en los diarios cordobeses de comienzos del siglo XX (1900-1914). Córdoba, Argentina: Jorge Sarmiento Editor.

Brunetti , P. (2008). Sensacionalismo y renovación en la prensa gráfica cordobesa. En P. Brunetti y otros, Ensayos sobre la prensa. Buenos Aires, Argentina: Ediciones Biblioteca Nacional.

Caimari , L. (2009). La ciudad y el crimen. Delito y vida cotidiana en Buenos Aires, 1880-1940. Buenos Aires, Argentina: Sudamericana.

Chartier, R. (1994) [1993]. Libros, lecturas y lectores en la Edad Moderna. Madrid, España: Alianza Editorial.

De Diego, J. L. (2009). Editores, libros y folletos. En C. Manzoni (Dir.), Historia Crítica de la Literatura Argentina. Rupturas. Buenos Aires, Argentina: Emecé Editores.

Eco U. (2013) [1979]. Lector in fabula. Buenos Aires, Argentina: Sudamericana.

Gramsci , A. (2006) Periodismo. La crónica policial. En Los intelectuales y la organización de la cultura. Buenos Aires, Argentina: Nueva Visión.

Lafforgue, J. y Rivera, J. (1996). Asesinos de papel. Ensayos sobre narrativa policial. Buenos Aires, Argentina: Colihue.

Link, D. (2003) El juego de los cautos. Literatura policial: de Edgar A. Poe a P.D. James. Buenos Aires, Argentina: La Marca.

Pastormelo , S. (2014) [2006] 1880-1899. El surgimiento de un mercado editorial. En J. L. De Diego (dir.), Editores y políticas editoriales en Argentina (1880-2010). México: Fondo de Cultura Económica.

Piglia , R. (2005) Lectores imaginarios. En El último lector. Barcelona, España: Anagrama.

Prieto , A. (1988) El discurso criollista en la formación de la Argentina moderna. Buenos Aires, Argentina: Sudamericana.

Rivera , J. (1986) El escritor y la industria cultural. En Capítulo. Historia de la Literatura argentina (Tomo II). Buenos Aires, Argentina: CEAL.

Rogers , G. (2008). Caras y Caretas: cultura, política y espectáculo en los inicios del siglo XX argentino. La Plata, Argentina: Universidad Nacional de La Plata.

Saítta, S. (2013) [1998]. Por el mundo del crimen. En Regueros de tinta. El diario Crítica en la década de 1920. Buenos Aires, Argentina: Siglo XXI Editores.

Saítta , S. (2009). Nuevo periodismo y literatura argentina. En C. Manzoni (Dir.). Historia Crítica de la Literatura Argentina. Rupturas. Buenos Aires, Argentina: Emecé Editores.

Saldías , J. A. (1968). La inolvidable bohemia porteña. Radiografía ciudadana del primer cuarto de siglo. Buenos Aires, Argentina: Editorial Freeland.

Setton, R. (2012). Los orígenes de la narrativa policial en la Argentina. Repercusión y transformación de modelos genéricos alemanes, franceses e ingleses. Madrid, España: Iberoamericana/Vervuert. 


\section{Notas}

1 Sherlock Holmes fue una revista semanal ilustrada que se publicó en Buenos Aires desde 1911 hasta 1913. El semanario fue dirigido por Juan B. Clara y alcanzó a tener una tirada de 50.000 ejemplares. Se distribuía en esa ciudad y en otras del interior país. Los lectores podían adquirir su ejemplar suelto a 20 centavos (25, en el interior) o suscribirse por una suma de $\$ 2,50 \mathrm{~m} / \mathrm{n}$ mensual. El material proporcionado giraba mayormente en torno a lo policial: crónicas nacionales y extranjeras, relatos policiales originales y traducciones de autores destacados del género, especialmente ingleses y franceses, al que se sumaba críticas teatrales y deportivas.

2 En las primeras décadas del siglo XX, asistimos a la culminación de un proceso a través del cual el periodismo se separa del poder del Estado para configurar un campo periodístico nuevo, congruente con los desarrollos de la prensa mundial. En pocos años, los diarios incorporaron tecnología, maquinarias y técnicas de impresión que sentaron las bases del periodismo de masas. En el marco de una economía en ascenso, se ampliaron las redes de distribución de periódicos y se inauguraron edificios modernos con nuevas rotativas que llegaron a imprimir 320.000 ejemplares, frente a los 48.000 de la tirada anterior (Saítta, 2009; 2013). La multiplicación de la prensa escrita posibilitó el inicio de nuevos emprendimientos que adecuaron sus formatos, su lenguaje, así como las modalidades de difusión y comercialización, en la realidad cambiante que el nuevo siglo traía aparejada (De Diego, 2009). Este crecimiento de la prensa es, asimismo, el emergente de la incorporación de amplios sectores sociales a la cultura letrada. A partir de entonces, dicha cultura se convirtió en un espacio plural y escindido en el que "debieron convivir, no sin conflictos, dos circuitos de producción y consumo culturales: un circuito culto y un circuito popular” (Pastormelo, 2014, p. 1). El circuito popular se nutrió básicamente de la prensa periódica. Como señala Adolfo Prieto: "la prensa periódica, previsiblemente, sirvió de práctica inicial a los nuevos contingentes de lectores, y la prensa periódica, previsiblemente también, creció con el ritmo que éstos crecían" (Prieto, 1988, p. 10)

3 La recepción de la revista en el campo periodístico contemporáneo da cuenta del carácter original de su propuesta. En el segundo número de Sherlock Holmes se recuperan las reseñas publicadas en diversos diarios y revistas a propósito de su aparición. Dichas reseñas destacan la originalidad del proyecto editorial. Por ejemplo, el periódico El Diario consigna lo siguiente: "SHERLOCK HOLMES, como su título lo indica, es una revista destinada á ocuparse preferentemente de la nota policial, nota que interesa como ninguna otra y que es, como ninguna otra, siempre nueva, emocionante, palpitante y de intensísima y profunda emoción". Otros periódicos siguen una línea similar: "Trae además -y en esto ya muestran sus uñas los detectives periodistas que forman parte de la redacción de SHERLOCK HOLMES- varias primicias policiales, que han de ser leídas con gusto por los infinitos aficionados á las crónicas de la delincuencia, primicias meritorias, en este ambiente metropolitano donde puede decirse ningún secreto permanece X para los chinos profesionales" (La Razón); "Todo lo más horripilantemente policial que exista se encuentra en SHERLOCK HOLMES. Crónica, novela, información gráfica. Original la cosa y de muy buena originalidad” (Sarmiento); “Tal es el epígrafe con que se presenta al público una nueva revista semanal ilustrada de índole completamente desconocida hasta el momento por nosotros, pero que sin duda ha de llenar el vacío que sienten los espíritus ávidos de lo interesantemente sensacional" (La Gaceta de Buenos Aires) (Sherlock Holmes, "Nuestro primer número", año I, no 2, 11 de julio de 1911).

4 Cabe recordar que para el momento de aparición de la revista ya se habían publicado en Argentina una serie de relatos protagonizados por el personaje de Conan Doyle: La señal de los cuatro (1898), "La mancha de sangre" (1898) y "La liga de los pelirrojos" (1899), entre otros.

5 El sensacionalismo constituyó una de las estrategias narrativas predominantes en la crónica policial de la prensa a comienzos de siglo XX (ver en este sentido la investigación de Paulina Brunetti Relatos de prensa. La crónica policial en los diarios cordobeses de comienzos del siglo XX. 1900-1914). En tanto escritura orientada a interpelar/impeler al lector, la crónica policial sensacionalista recurre a la utilización de una serie de estrategias conocidas por el lector, basadas en la redundancia y el estereotipo. Como señala Paulina Brunetti: "Su discurso no procuraba tanto expresar las emociones del cronista sino especialmente suscitarlas en el lector a partir de la tematización de un mundo ya cargado de fuerza patémica en el imaginario social (...) ¿Cuáles fueron sus artificios retóricos? En principio, una combinatoria que se centra en una adjetivización con fuerte propiedades patemizantes o en figuras que hacen a la amplificación como la hipérbole y la hipotiposis. Es por ello que suele destacarse como característico del sensacionalismo su estilo al que se denomina \#melodramático\# cuya característica, aunque no la única, fue la exageración y sobre todo la exasperación de las pasiones" (Brunetti, 2011, pp. 3-4). La intención de diferenciarse de este tipo de crónicas por parte de la revista es explicitada en la reseña que el periódico El Diario publica a raíz de la aparición de Sherlock Holmes y que la propia revista recupera en sus páginas la semana siguiente: "La revista policial puramente populachera murió para siempre, $-\mathrm{y}$ bien muerta está- al fenecer \#Los Sucesos\# y sus posteriores imitadores á causa de la mayor progresiva mayor cultura del público. Pero si para aquella revista que sólo halagaba bajas pasiones ya no hay público -y más vale que no lo haya- tiene que haberlo numerosísimo para una publicación policial á la moderna, literariamente bien escrita y bien informada, que 
sea cada semana el compendio acertadamente extractado de todos los acontecimientos policiales de la misma (Sherlock Holmes, "Nuestro primer número", año 1, n 2, 11 de julio de 1911).

6 A fines del siglo XIX y comienzos del XX, ya se habían publicado en el país diversas obras del género. Entre las más representativas, podemos mencionar a las siguientes: El derrumbamiento (1879), El crimen de Orcival (1880), El expediente número 113 (1881) y Elproceso Lerouge (1881) de Émile Gaboriau; "La casa vacía” (1894) de Maurice Leblanc, además de los relatos de Conan Doyle ya mencionados (Lafforgue y Rivera, 1996; Setton, 2012).

7 Entendemos, siguiendo a Link, a la literatura como una máquina que procesa o fabrica matrices de percepción: ángulos, puntos de vista, relaciones, grillas temáticas, principios formales. En términos del autor: "Lo que se perciba será diferente según el juego que se establezca entre cada uno de los factores que forman parte de la práctica literaria. El policial, naturalmente, es una de esas matrices perceptivas" (Link, 2003, p. 9).

8 Lila Caimari señala que: "Acostumbrados a reconocer a los personajes de la calle de memoria, por el simple conocimiento de primera mano, los vigilantes (en su mayoría criollos, muchos reclutados en las provincias) se ven completamente desbordados. Entre 1870 y el cambio de siglo, esta sensación de rezago no los abandona, y en ese clima institucional se acumulan los documentos que hablan del temor al caos (la mayoría de los arrestos de esos años no son por delitos contra las personas o la propiedad, sino por "desorden público"). Es que este universo fisonómico al que cada semana se incorporan nuevos miles de individuos ya no puede ser controlado con la mirada de un agente de la calle, por más sagaz que sea. El repertorio de rostros familiares a vigilar va siendo ahogado en un mar de caras nuevas: a fuerza de multiplicación, las combinaciones de narices, cejas, ojos, bocas y peinados se van desdibujando, excediendo completamente los límites de la memoria humana. Problema crucial, porque esa multitud que se traga las singularidades de la fisonomía es el mejor escondite de las intenciones: cobija mayores permisividades y puede albergar las ideologías y moralidades más inconfesables (2009, pp. 41-43).

9 "Según el registro del segundo Censo Nacional en 1895, la población del país alcanzaba prácticamente los 4.000.000 de habitantes, de los cuales el 34\% eran extranjeros. Para el tercer Censo, levantado en 1914, la población casi se había duplicado, con 7.885.000 habitantes, con un porcentaje elevado ahora al 43\% de extranjeros" (Prieto, 1988, p. 13).

10 Walter Benjamín ha sido uno de los primeros en señalar la ansiedad por el costado intranquilizador y amenazante que generó el crecimiento demográfico en las grandes ciudades. La vida en las metrópolis modernas es atravesada por la percepción del otro como un criminal: "Aquí la masa aparece como el asilo que protege al asocial de sus perseguidores. Entre sus aspectos más peligrosos, este fue el más manifiesto” (2012, p. 104).

11 Como señala Lila Caimari, tal vinculación no es nueva. La idea de la metrópoli moderna como escenario del crimen ha estado con fuerza presente en la literatura y la prensa masiva desde mediados del siglo XIX y se convirtió en un elemento clave de la imaginación social del período "como lo revela el éxito de las narraciones de \#misterios de la ciudad\#, que llenan las columnas de la prensa europea (y pronto son traducidas y publicadas en tantos diarios y revistas porteños)" (2009, p. 45).

12 Ya Antonio Gramsci señalaba, respecto de la utilización de procedimientos ficcionales en la escritura de la crónica policial, lo siguiente: "Es fácil observar que la crónica de los grandes diarios se redacta como una inacabable Mil y una noches que se concibe con rasgos de novela por entregas. Existe la misma variedad de esquemas sentimentales y de motivos: la tragedia, el drama frenético, la intriga ingeniosa e inteligente, la farsa. El Corriere della Sera no publica novelas por entregas, pero su página policial tiene todas sus características con el agregado de la noción, siempre presente, de que se trata de hechos verdaderos" (2006, p. 181).

13 Se respeta la escritura consignada en el original.

14 La revista publica las traducciones de estos relatos en algunos casos apenas semanas después de su aparición en Europa. Por ejemplo, "Los juegos del sol", serie perteneciente a las Confidencias de Arsenio Lupin, de Maurice Leblanc se publica el 4 de julio de 1911, a tres meses de su edición en Francia (15 de abril de 1911); o "La desaparición de Lady Frances Carfax", de Arthur Conan Doyle, que aparece en Sherlock Holmes el 19 de diciembre de 1911 a diez días de su publicación en The Strand Magazine.

15 La publicación de representaciones gráficas ligadas a eventos policiales o accidentes urbanos en las revistas no era algo novedoso. Sandra Szir señala al respecto que "La relación entre crimen e imagen presentaba ya un desarrollo en los periódicos europeos y norteamericanos, cuyos editores -y en particular los de los semanarios populares ilustradoshabían detectado que el registro sensacionalista de los desastres humanos podía implicar buenos negocios" (2009, p. 22). En nuestro país, los antecedentes se remontan a las publicaciones de la Revista de Policía (1871) y la Revista Criminal (1873). 